\title{
Treatment of complicated case with subclavia steal syndrome and stenosis of common iliac artery
}

\author{
Bujar Gjikolli ${ }^{1}$, Besima Hadžihasanović ${ }^{2}$ Suad Jaganjac ${ }^{3}$, Edin Herceglija ${ }^{4}$, \\ Maida Nikšić ${ }^{1}$, Amel Hadzimehmedagić ${ }^{5}$, Mirza Dilićc ${ }^{6}$, Emir Solaković ${ }^{7}$, \\ Zulejha Merhemić ${ }^{1}$, Šerif Bešlić ${ }^{8}$, Lidija Lincender ${ }^{9}$, Ramë Miftari $^{10}$
}

${ }^{1}$ Neuroradiology Department, Institute of Radiology, KCU Sarajevo, Bosnia and Herzegovina,

${ }^{2}$ Muskuloskeletal Department, Institute of Radiology, KCU Sarajevo, Bosnia and Herzegovina,

${ }^{3}$ Klinikum Eilbek Hamburg, Germany, ${ }^{4}$ Vascular Department, Institute of Radiology,

KCU Sarajevo, Bosnia and Herzegovina ${ }^{5}$ Clinic for Orthopedics and Traumatoology,

KCU Sarajevo, Bosnia and Herzegovina, ${ }^{6}$ Clinic for Vascular Diseases, KCU Sarajevo,

Bosnia and Herzegovina, ${ }^{7}$ Clinic for Vascular Surgery, KCU Sarajevo, Bosnia and Herzegovina,

${ }^{8}$ Thoracic Department, Institute of Radiology, KCU Sarajevo, Bosnia and Herzegovina,

${ }^{9}$ Abdominal Department, Institute of Radiology, KCU Sarajevo, Bosnia and Herzegovina,

${ }^{10}$ Institute of Radiology, Nuclear Medicine Dep., UCC of Kosova, Pristhinë, Republic of Kosova

\begin{abstract}
Background. The aim of this case report is to describe the realization of complex radiological minimally invasive interventional procedures at the Institute of Radiology in KCU Sarajevo during which we treated a very complicated case with the left subclavia steal syndrome and the stenosis of the left common iliac artery.
\end{abstract}

Case report. The patient was 57 years old with previous history of ischemic lesions in brain, with occlusion of the left arteria carotis communis (ACC) and stenosis of the right arteria carotis interna (ACI), with dizziness and inability to look upward. The patient was treated first with subintimal recanalization and introduction of self-expandable stent into the left subclavia artery to compensate for the very wide remnant of the occluded artery. After four months of follow up with no change, our team attempted to treat stenosis of the right ACI but failed to do so and during this procedure in-stent restenosis in the left subclavia artery was noted. After less than two weeks we performed balloon dilatation of in-stent restenosis of a previously installed stent into the left subclavia artery. The patient underwent CT and CT angiography (CTA), colour Doppler ultrasonography (CDUS), MRI and MR angiography (MRA) before and after the procedures.

Conclusions. A follow up and, if needed, a balloon dilation are necessary to prevent the re-occlusion of the previously treated subclavia artery with stenting.

Key words: subclavia steal syndrome; intentional subintimal recanalisation; restenosis; balloon dilation

Received 13 August 2007

Accepted 21 August 2007

Correspondence to: Bujar Gjikolli M.D., Radiologist, Institute of Radiology, University Clinical Centre of Kosova, Pristine, Kosova; E-mail: bujargjikolli@yahoo. com

\section{Introduction}

Subclavia steal syndrome (SSS) is a group of signs and symptoms resulting from 
steno-occlusive disease proximal to the origin of the vertebral artery, in which the arterial flow is reversed. ${ }^{1-4}$ It was described in 1960 for the first time, and the association between this phenomenon and neurologic symptoms was recognized in $1961.5,6$, SSS refers to the retrograde vertebral artery flow associated with transient neurologic symptoms related to cerebral ischemia while subclavia steal phenomena (SSP) refer to the retrograde flow in the vertebral artery only.

Stenosis or occlusion of the proximal subclavia artery causes a reversed vertebral flow with resulting decreased blood pressure in the arm distal to the steno-occlusive disease. A reduced blood pressure causes the ipsilateral vertebral artery blood flow alteration as a compensatory pathway through the arm, and this sign confirms subclavia disease proximal to the origin of the vertebral artery. Other potential collateral pathways include those between the external carotid artery (ECA) and the subclavia artery from occipital branches of ECA and the superior thyroid artery of ECA to the inferior thyroid artery branch of thyrocervical trunk. There are four types of subclavia steal, defined by territory from which blood is "stolen" in SSS: vertebrovertebral, carotid-basilar, external carotidvertebral, and carotid-subclavia. ${ }^{7}$ Based on vertebral hemodynamic changes, SSS has three defined stages: reduced antegrade vertebral flow (stage I), reversal of flow during reactive hyperemia testing of the arm (stage II), and permanent retrograde vertebral flow indicating subclavia artery occlusion (stage III). ${ }^{8}$

Arm symptoms can be provoked during arm exercise or peripheral reactive hyperaemia, while neurological symptoms occur when compensatory flow to the subclavia artery from the vertebral artery diverts too much flow to the arm and away from brain. Neurologic symptoms result primarily from the insufficient intracranial circulation through circle of Willis mainly through the posterior communicating artery. Absence of a posterior communicating artery, extra cranial carotid artery stenosis and higher flow toward the arm can cause neurologic symptoms. The spontaneous resolution of vertebro-basilar symptoms may be related to the establishment of extra cranial collaterals to the subclavia circulation.

Etiology of SSS is predominantly atherosclerotic in people older than fifty years of age. In Asians Takayasu arteritis as etiology can be seen in up to $36 \%$ of the population. Other causes of SSS include giant cell arteritis, tumour encasement, trauma, previous surgical procedure such as aortic stentgraft placement for thoracic dissection or aneurysm, coarctation of aorta with the obliteration of subclavia orifice, extra vascular obstruction, hypoplasia / atresia or isolation of subclavia artery with the anomalous aortic arch, vascular ring, ligation for the correction of tetralogy of Fallot or co-arctation of aorta. ${ }^{9}$

The risk of stroke seems low ${ }^{10}$ but patients with SSS can be severely debilitated by arm and intracranial ischemia symptoms. As many as $15 \%$ of initially asymptomatic patients can experience vertebrobasilar transient ischemic attacks during two years of follow up. ${ }^{11}$

SSS is more frequent in males than females with incidence 1.5-2:1 while Takayasu arteritis is more common in females. SSS has a left-sided to right-sided ratio of 3-4:1 as a result of turbulence-related atherosclerosis of the acutely angled left subclavia artery.

Symptoms include dizziness, unsteadiness, vertigo, vision changes, arm ischemia causing arm claudication and rest pain, focal sensory or motor loss, dysphasia, and unilateral visual disturbances. Symptoms may develop during the exercise of the upper limbs, when blood is deviated from the vertebro-basilar system to the upper limb. 
A reduced blood pressure with change of $>20 \mathrm{~mm} \mathrm{Hg}$ when compared with contra lateral arm, weak or absent radial and ulnar pulse are other signs suggesting SSS.

Colour Doppler US is the preferred examination. ${ }^{12}$ CT visualizes calcifications related to atheroma. Contrast enhanced CT angiography (CTA) can visualize the degree of subclavia artery stenosis or occlusion, including other changes in the arteries; mural thrombus, ulceration, and arterial wall calcification can be evaluated.

MRI and contrast enhanced 3-D MR angiography (MRA) after localizing 2-dimensional time-of-flight can also confirm SSP. Phase-contrast MRA measures the vertebral artery flow direction and velocity. ${ }^{13-15}$

SSS can be treated with minimally invasive radiological procedures of percutaneous transluminal angioplasty and stenting if angioplasty fails, using balloon-expandable stents or in some cases self expandable stents. ${ }^{16-22}$ Vertebro-basilar stroke during interventional procedures is rare due to the delayed establishment of the ante grade flow in the vertebral artery after the angioplasty/stenting. A distal protection may be useful especially in cases with thrombosis/unstable plaque.

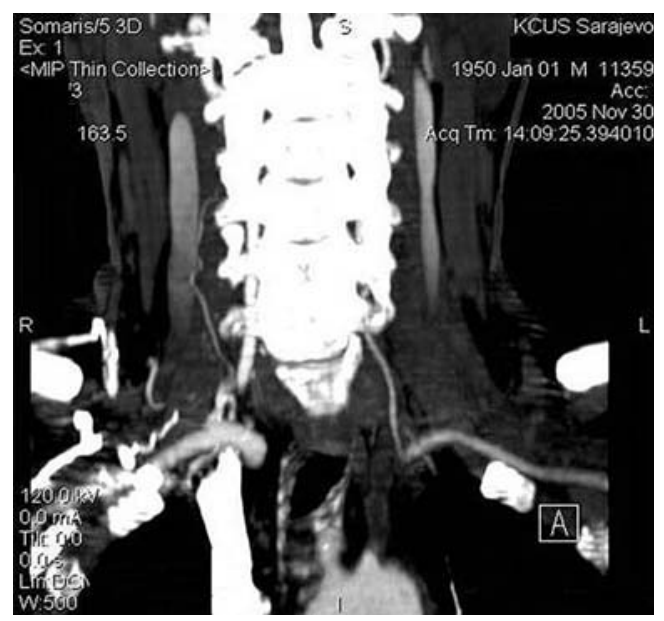

Additionally SSS can be treated with surgical revascularization using either synthetic graft or saphenous vein grafts. Invasive options include carotid-subclavia bypass (CSB), carotid-subclavia transposition (CST), and axillo-axillary bypass. ${ }^{23-26}$

With this presentation we would like to describe the realization of complex radiological interventional therapeutic procedures of treating subclavia steal syndrome and stenosis of the left common iliac artery, at the institute of Radiology KCUS under the supervision of a Bosnian expert Dr. Suad Jaganjac working at the Hamburg Klinik Eilbek in Germany.

\section{Case report}

A 57-year-old male patient had complained of multiple symptoms, including weakness, dizziness, inability to look upward, speech difficulties and difficulties in using his left hand, in the five years following cerebral vascular insult. In 2002 he was admitted to the vascular surgery hospital KCUS because of atherosclerotic changes with stenosis of arteria carotis communis (ACC) and arteria carotis

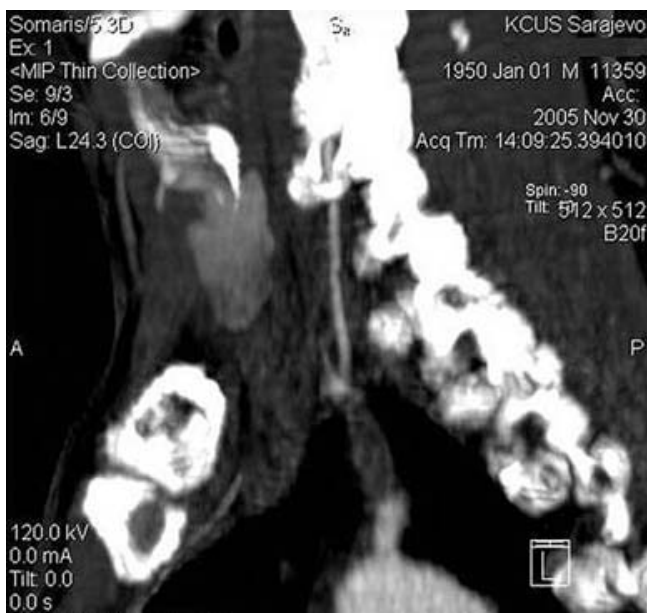

Figure $1(\mathbf{a}, \mathbf{b})$. CT angiography (CTA) maximum intensity projection (MIP) reformats show the occlusion of the left subclavian artery and the left brachial artery receiving blood from the left vertebral artery- steal syndrome. 
interna (ACI) in the left side. In 2003 he was hospitalized in the clinic for cardiovascular diseases in UCC Tuzla where surgeons confirmed stenosis of the right ACI but did not intervene in the artery. The patient also complained for claudi-
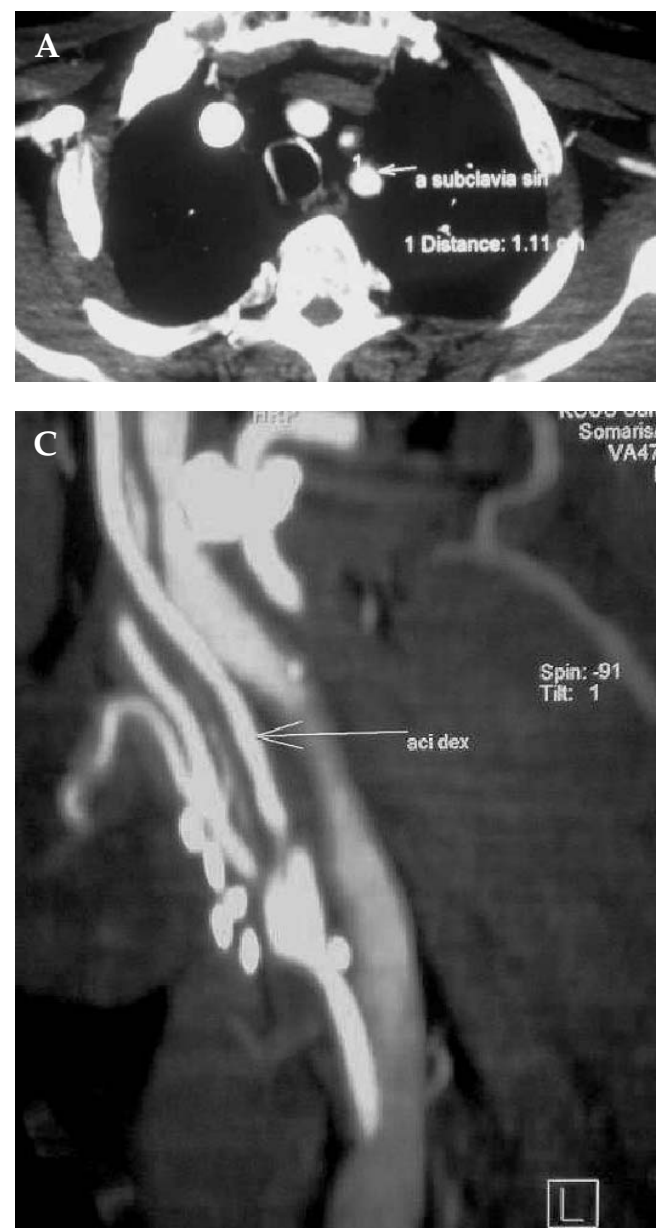

Figure $2(\mathbf{a}, \mathbf{b}, \mathbf{c}, \mathbf{d})$. CTA reconstructed images show the occlusion of left common carotid artery (ACC) less than $1 \mathrm{~cm}$ from the aortic arch with the reconstruction of left internal carotid artery (ACI) through collaterals coming from left external carotid artery (ACE). The occlusion of the left subclavia artery approximately 1 $\mathrm{cm}$ from its origin with its reconstruction in the level of origin of the vertebral artery and severe stenosis of right $\mathrm{ACI}$ in its initial part. cating pain in his legs after 20 meters of walking. He had high blood pressure and increased triglycerides in blood but was not diabetic. He quit smoking in 2002 after more than 40 years of $1-1.5$ packages of cigarettes per day.
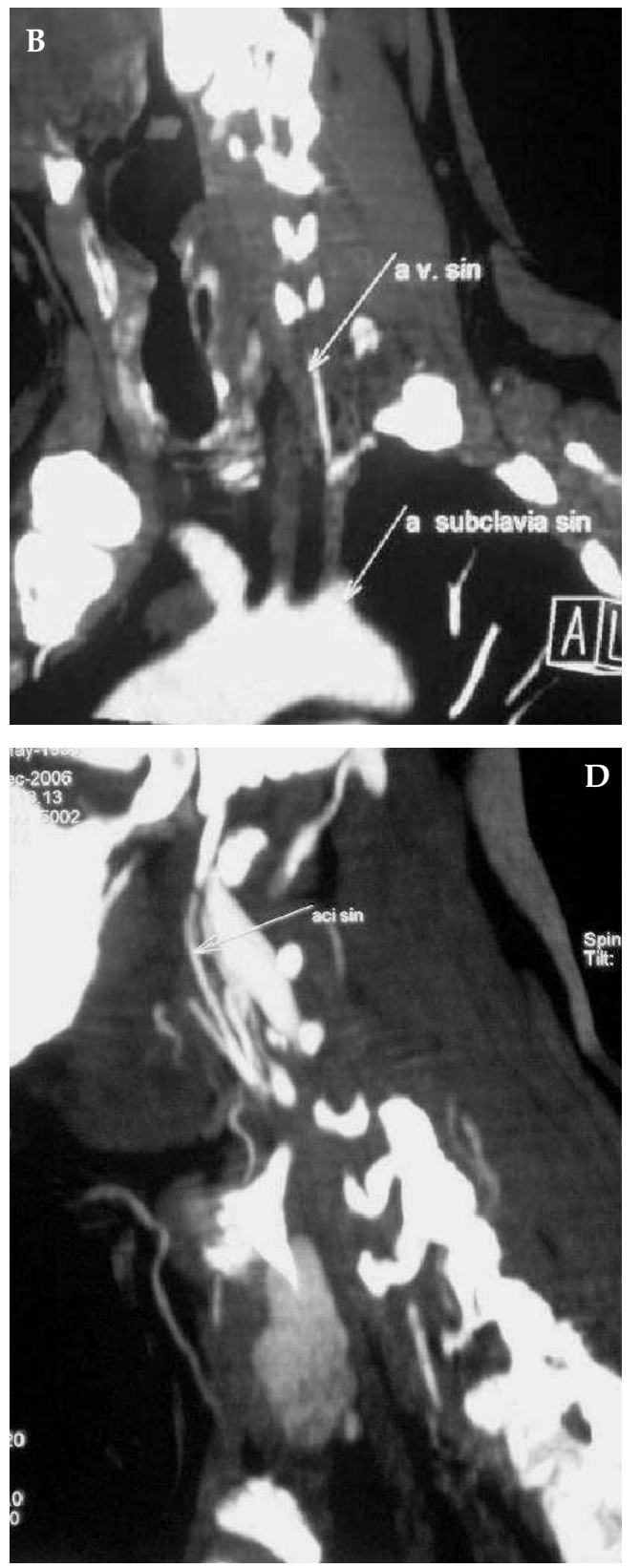

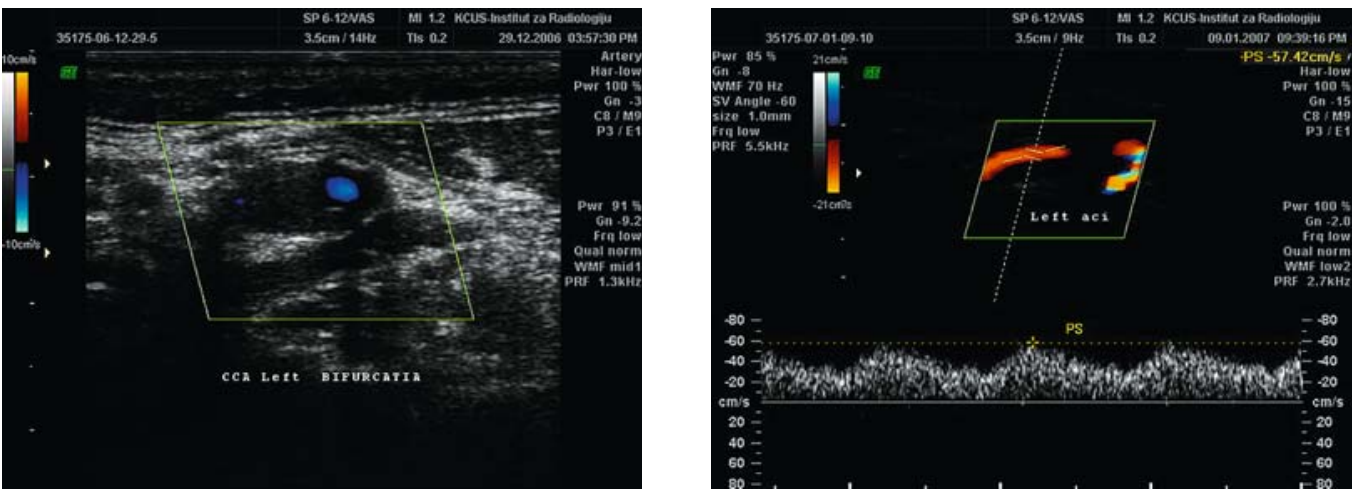

Figure $3(\mathbf{a}, \mathbf{b})$. Colour Doppler ultrasound (CD US) showing flow in the left internal carotid artery (ACI) and ACE above the occluded left common carotid artery (ACC).

In November 2005, the patient complained of ongoing symptoms and underwent CTA at our institute (Figure 1). The occlusion of left ACC and left subclavia steal syndrome was diagnosed but no interventions were performed.

In December 2006 the patient was referred for CTA again and the occlusion of left ACC and left subclavia artery reconstructed through the left vertebral artery was shown. The remnant subclavia artery below the occlusion was measured at $1.11 \mathrm{~cm}$. High grade stenosis of right ACI has been shown too. Left ACI was reconstructed through collaterals coming mainly through arteria carotis externa (ACE) branches (Figure 2). During discussion, the patient mentioned physicians' previous difficulties

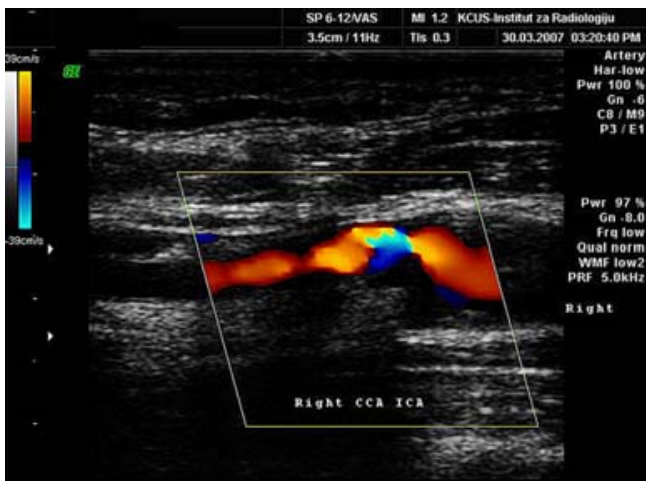

doctors had accessing his femoral artery for diagnostic digital subtraction angiography (DSA). Additional CTA of abdominal aorta and the upper part of his lower extremities confirmed mild stenosis of the right femoral artery and significant stenosis of the left common iliac artery.

Additionally colour Doppler ultrasound (CD US) confirmed the changes seen in the CTA: the disturbance of the flow and the steal syndrome in the left side (Figures 3, 4). Left ACC showed maximum diameter of $6.5 \mathrm{~mm}$ without detectable flow while in ACI and ACE portion there was flow detectable coming from surrounding collaterals. Right ACC had maximum diameter of $7 \mathrm{~mm}$ with intima medial thickness of 1.3 $\mathrm{mm}$ with laminar flow and Peak Systolic

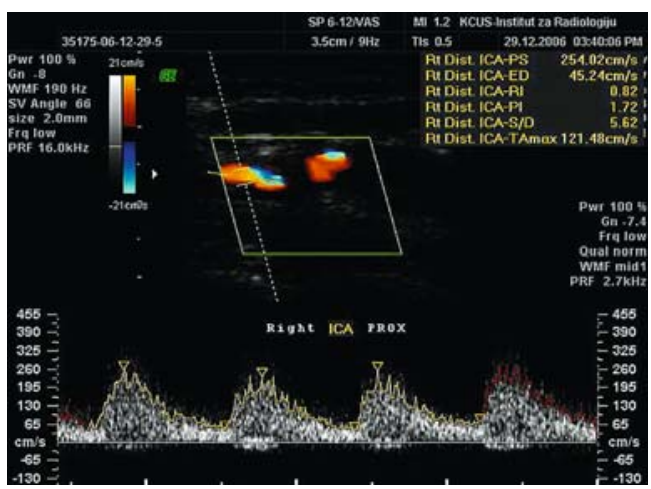

Figure $4(\mathbf{a}, \mathbf{b})$. Colour Doppler ultrasound (CD US) images showing stenosis of the initial part in the right arteria carotis interna $(\mathrm{ACI})$ and its increased spectral values. 

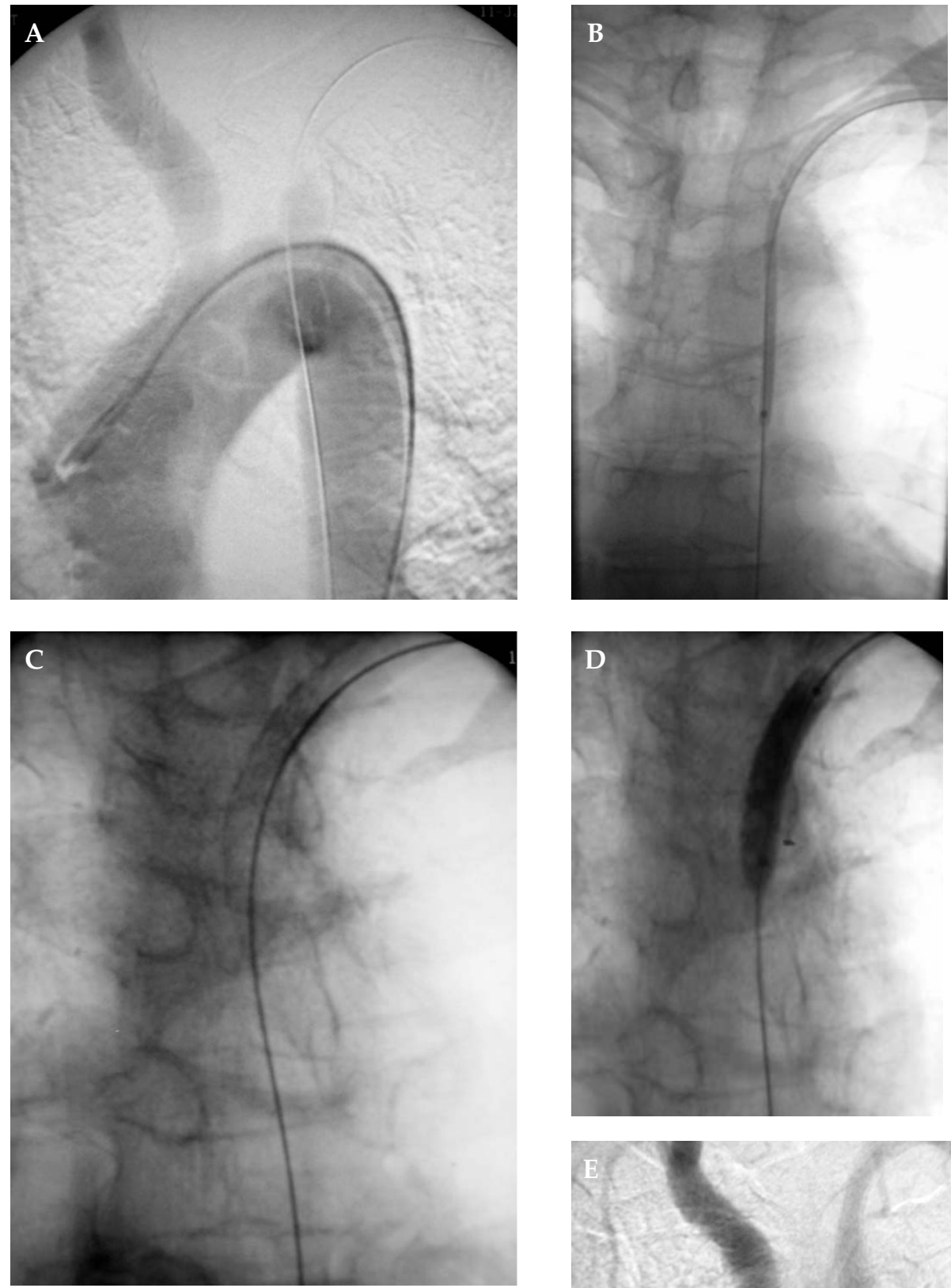

Figure 5 (a, b, c, d, e). Steps of the procedure performed. Subintimal recanalization, pre stenting balloon dilation, introduction of the stent with additional balloon dilatation giving the final result and preserving the vertebral artery which fills with contrast immediately after filling the aortic arch.

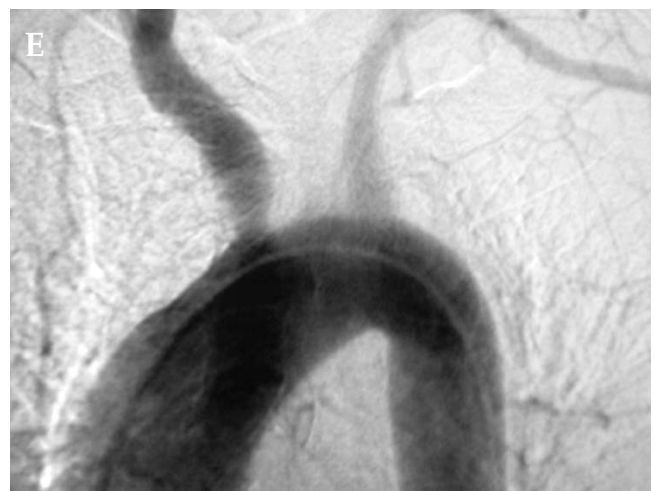



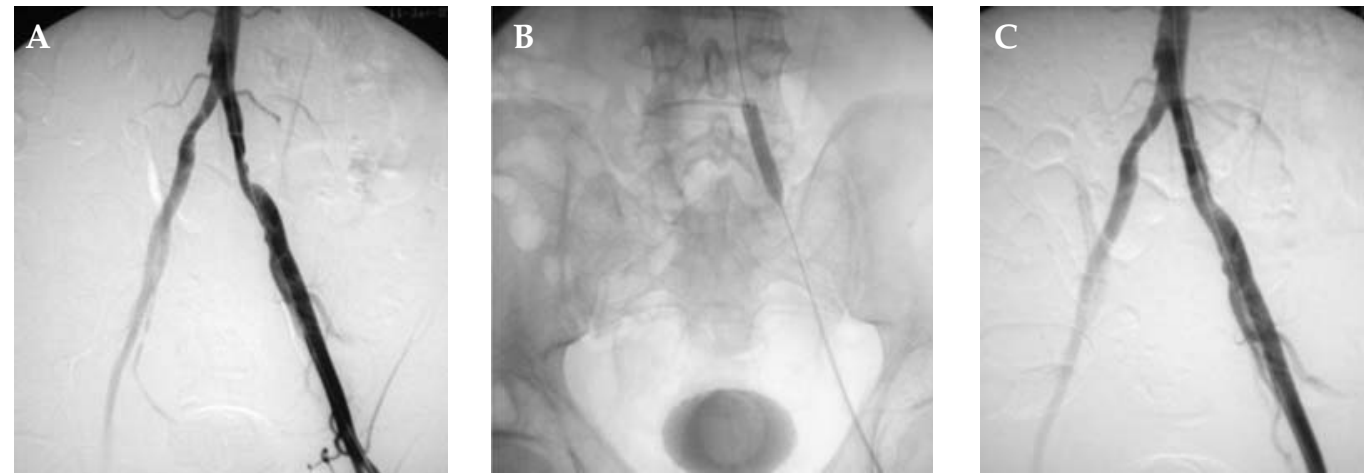

Figure $6(a, b, c)$. Stenosis of the left iliac artery before stenting and result gained after stenting.

Velocity (PSV) $91.43 \mathrm{~cm} / \mathrm{s}$ and End Diastolic Velocity (EDV) $21.33 \mathrm{~cm} / \mathrm{s}$ in its proximal part and turbulent flow with PSV 79.49 $\mathrm{cm} / \mathrm{s}$, EDV $32.56 \mathrm{~cm} / \mathrm{s}$ in its distal part. The dorsal part of the bifurcation and the initial part of the right ACI showed partly hyperand partly hypo-echogenic plaque inside the lumen, reducing its width $3.5 \mathrm{~mm}$ with increase of PSV to $254.02 \mathrm{~cm} / \mathrm{s}$ and EDV $45.24 \mathrm{~cm} / \mathrm{s}$.

After analyzing all imaging procedures performed, we decided to offer the patient treatment of subclavia syndrome while avoiding treating the stenosis of the right ACI as the only big artery supplying his brain with blood. He agreed and the procedure was performed in January 10, 2007 at the Institute of Radiology - KCU Sarajevo.

We used a left brachial approach and a hydrophilic guiding wire to perform Bolia's intentional subintimal recanalization. After reaching the aorta the guiding wire was pulled out with a goose neck snare from the introducer in the left femoral artery. Meanwhile this introducer was installed to confirm the position of the guide wire in
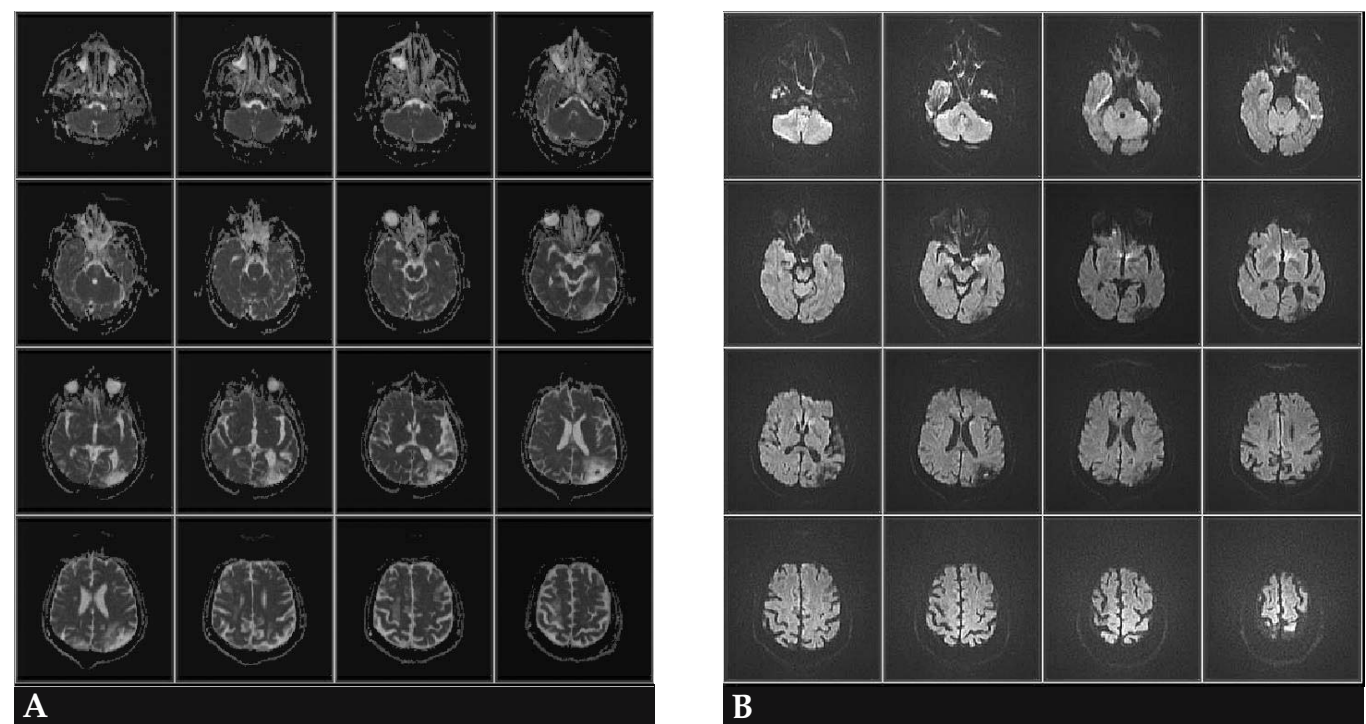

Figure $7(\mathbf{a}, \mathbf{b})$. Diffusion-weighted imaging (DWI) and apparent diffusion coefficient (ADC) images show old ischemic lesions and no new ischemic lesions at all. 


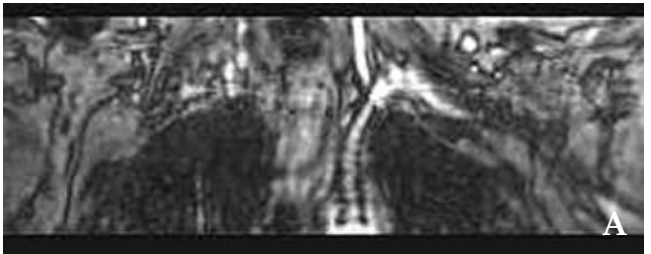

Figure $8(\mathbf{a}, \mathbf{b})$. Maximum intensity projection (MIP) MR reconstructions after stenting showing position and the patency of the left subclavian and left vertebral arteries.

the right lumen inside aorta. With a $3 \times 120$ $\mathrm{mm}$ balloon, we dilated the recanalized subclavia artery to create space for passing the stent. We used a self expandable stent to address both the wide proximal portion of the left subclavia artery and its narrow distal part. After introducing a self expandable stent, size $10 \times 44 \mathrm{~mm}$, the ad-
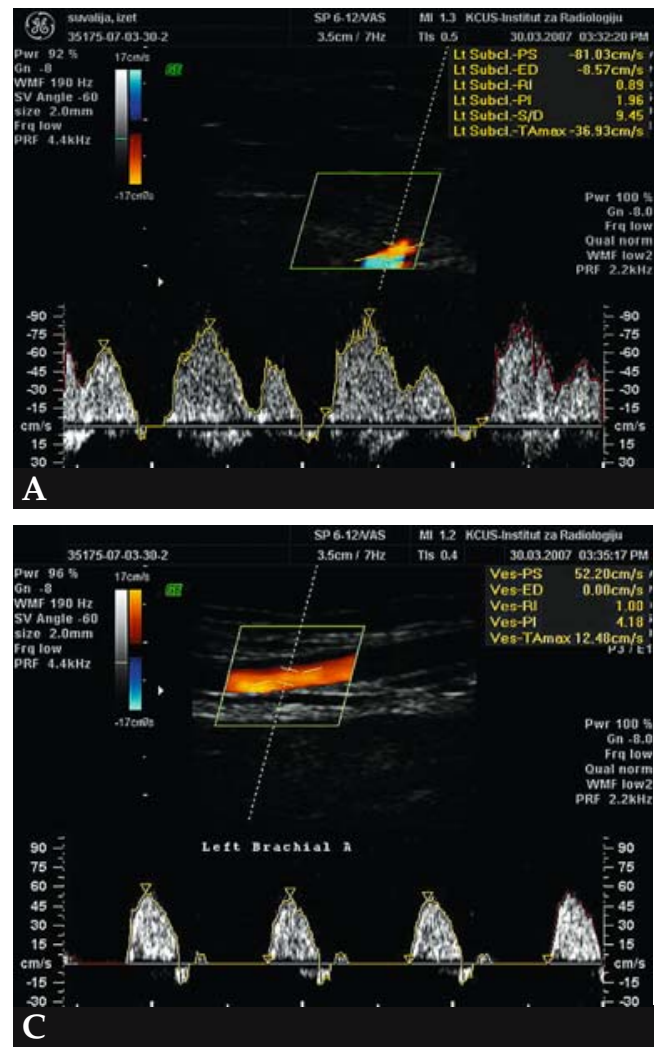

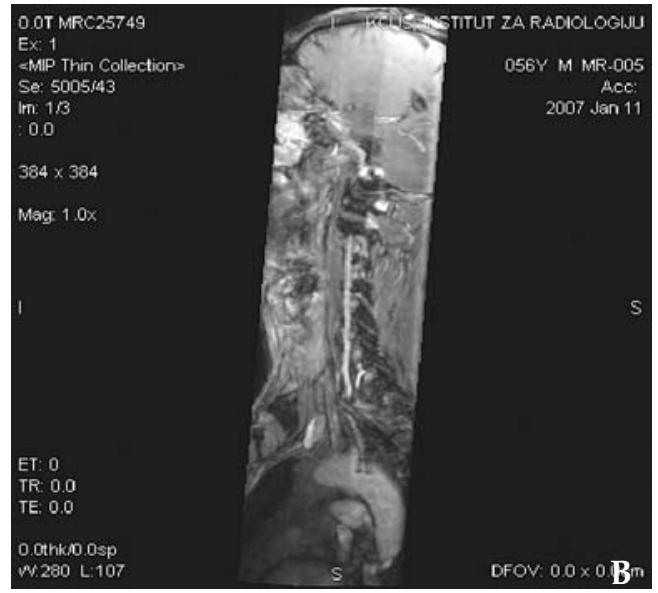

ditional balloon dilation to a width of $6 \mathrm{~mm}$ achieved satisfactory lumen diameter of the recanalized left subclavia artery. Tip of the
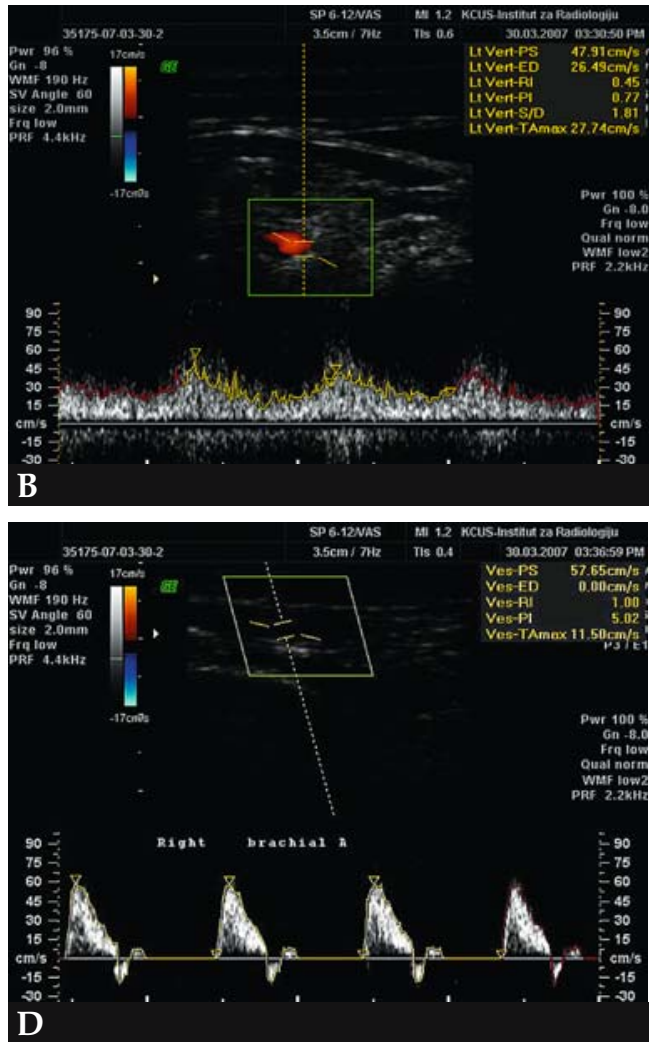

Figure 9 (a, b, c, d). Post procedural follow up with colour Doppler ultrasonography (CDUS) showing good flow in the left subclavian and vertebral arteries, and resulting good flow in the left brachial artery similar to the one in the right side. 

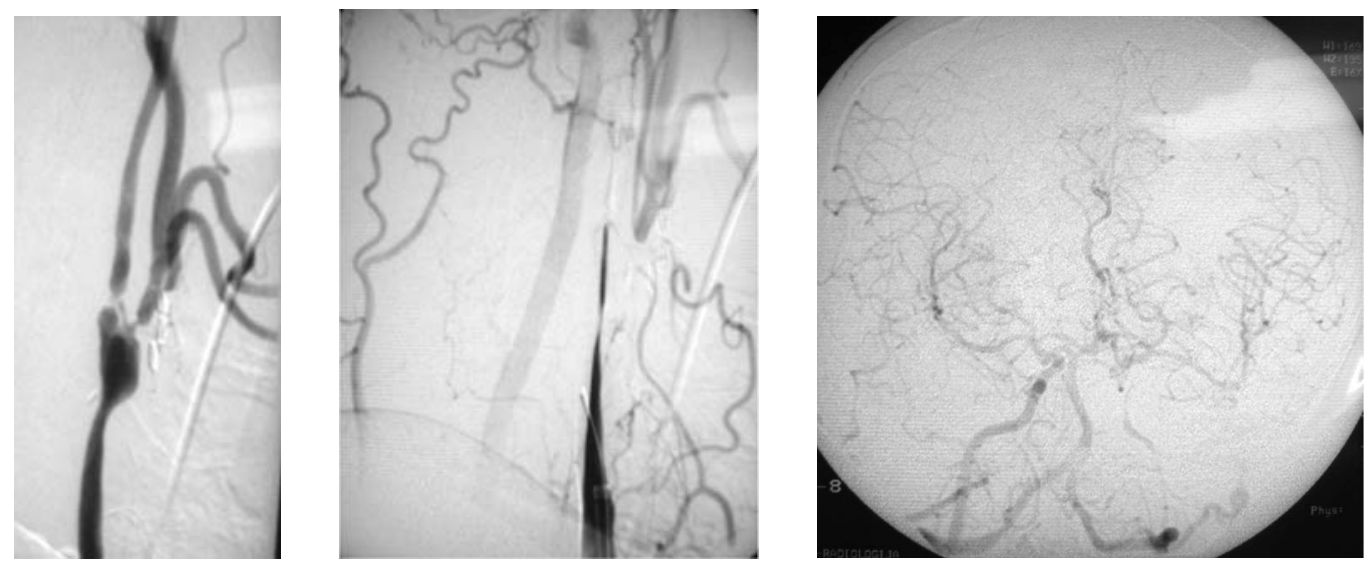

Figure $10(a, b, c)$. Working position of the right arteria carotis communis (ACC) before attempt for its stenting and after the dissection made. Brain angio after dissection without new changes.

stent was put several millimetres below the starting point of the left vertebral artery with the proximal part of the stent in the aortic arch lumen (Figure 5).

In the same procedure, the stenosis of the left common iliac artery was treated by introducing a stent $9 \times 38 \mathrm{~mm}$ on balloon with immediate results (Figure 6).

One hour after the procedure the patient was transferred to the MRI unit to assess consequences to the brain (Figure 7) and to confirm the position and the patency of implanted stent in the left subclavia artery (Figure 8).

Diffusion weighted imaging sequences showed only old and no fresh ischemic lesions. The day of the procedure, the patient was able to look up, walk without dizziness and use his left arm freely.

Patency of the left subclavia and vertebral arteries was followed with Doppler US, confirming a good flow after more than three months. A comparison between right and left brachial arteries confirmed the identical flow (Figure 9).

The patient was very satisfied with the results and insisted on an attempt to stent the right internal carotid artery. Initially, we were reluctant to do so because of high risks for the patient if the procedure failed, but we felt we could not deny him the chance of success, and we offered him a place in a group trial. On May 18, 2007 our team tried to perform stenting of the right internal carotid artery but failed to pass through the stenosis. The attempt resulted in dissection of the right ACC (Figure 10) most probably

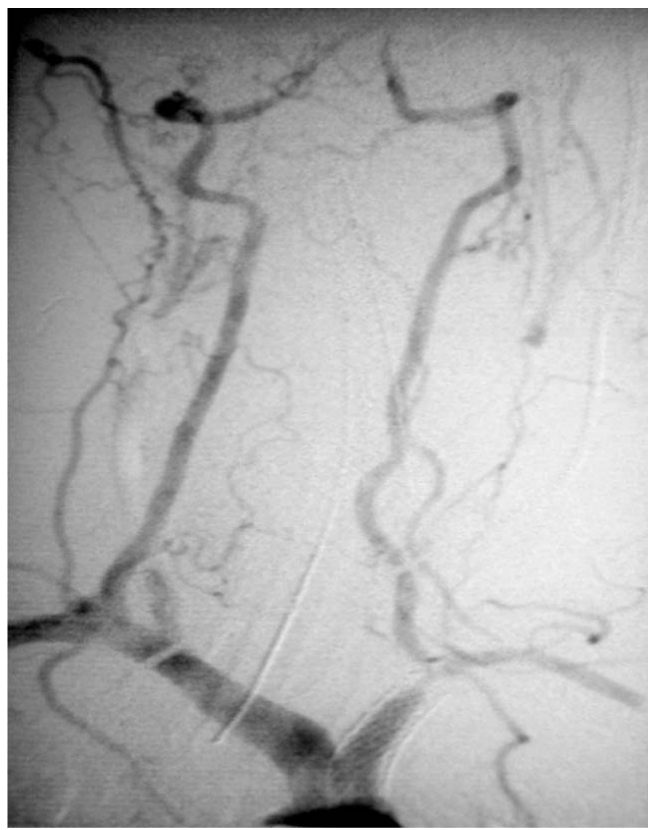

Figure 11. Narrowing of the distal part of the stent in the right subclavian artery. Occlusion of both carotid arteries. 

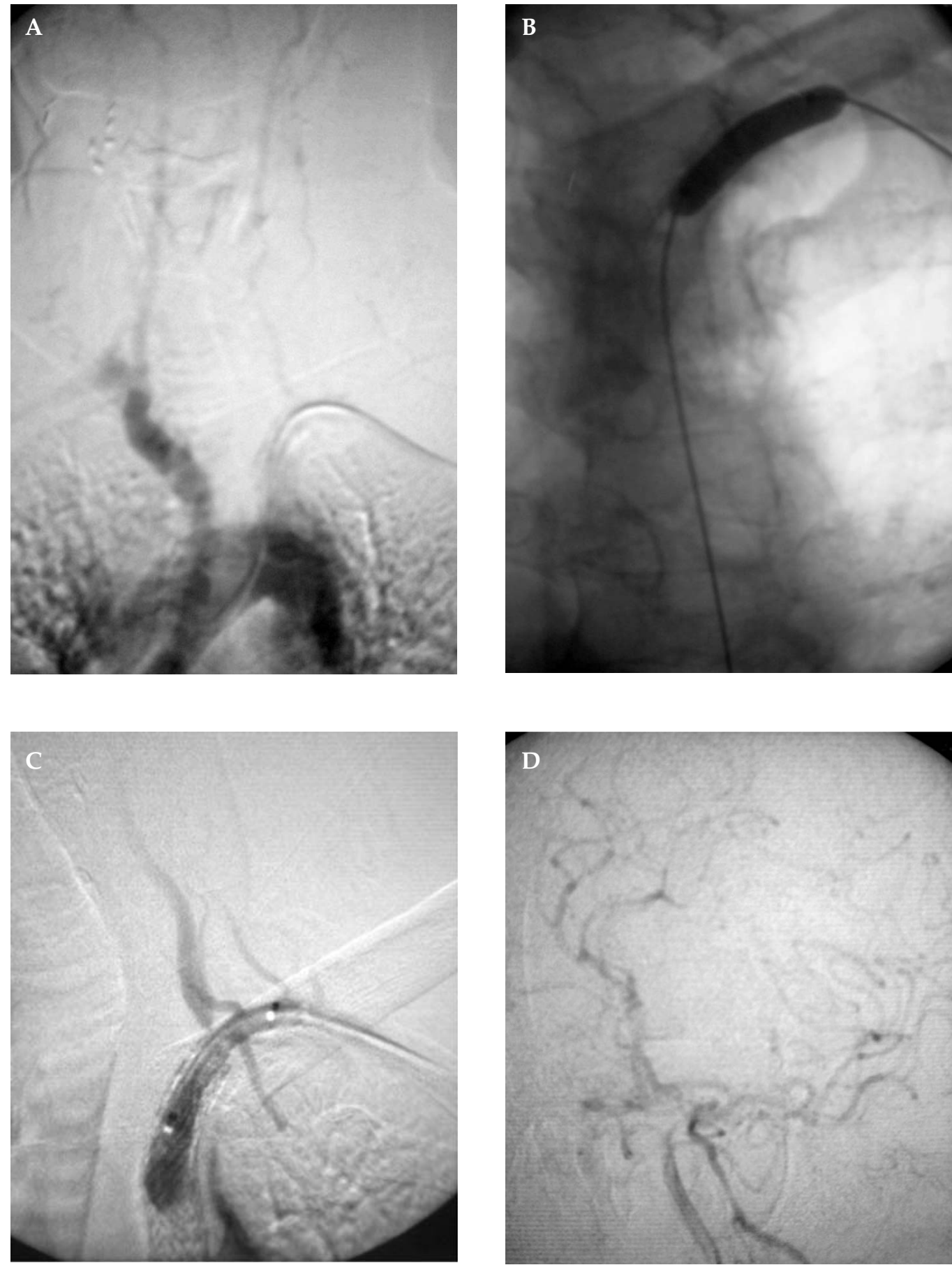

Figure $12(a, b, c, d)$. Steps of the procedure of treating the in-stent stenosis in the left subclavian artery and confirming the result without impact in brain blood supply. Stenosis of initial part of the left vertebral artery. 
because our college used hydrophilic guide wire for exchanging the long sheath introducer. No other consequences were found.

During this procedure, we noted that the distal part of the stent implanted in the right subclavia artery was narrower than before (Figure 11). The patient has begun complaining of pre-procedural symptoms, including dizziness, not being able to look up and difficulties to use his left arm.

On May 30, 2007 we performed the dilatation of the re-stenosed stent in the left subclavia artery. Through a left brachial approach, we performed dilatation with a balloon $4 \times 30 \mathrm{~mm}$; followed by a balloon sized $7 \times 50 \mathrm{~mm}$. The satisfactory lumen was achieved. Stenosis of the initial part of the left vertebral artery was identified and remains to be followed and for planning the possible treatment (Figure 12). Following the procedure the patient reported no recurrence of symptoms.

\section{Conclusions}

The immediate improvement in the patient's symptoms is a strong motivator for minimally invasive radiological interventional procedures. A follow up is necessary to prevent the re-occlusion of the artery, and the balloon dilation may be necessary to maintain the effect of the intervention. The patient's interest in such procedures is a crucial component for success.

\section{References}

1. Shadman R, Criqui MH, Bundens WP, Fronek A, Denenberg JO, Gamst AC, et al. Subclavia artery stenosis: prevalence, risk factors, and association with cardiovascular diseases. J Am Coll Cardiol 2004; 44: 618-23.

2. Morris PJ, Wood WC. Oxford Textbook of Surgery. 2nd edition. Oxford: OUP; 2000 .
3. Horrow M, Stassi J. Sonography of the Vertebral Arteries. A Window to Disease of the Proximal Great Vessels. AJR Am J Roentgenol 2001; 177: 539.

4. McIntyre K. Subclavia Steal Syndrome. eMedicine 2007.

5. Contorni L. The vertebro-vertebral collateral circulation in obliteration of the subclavia artery at its origin. [Italian]. Minerva Chir 1960; 15: 268-71.

6. Reivich M, Holling HE, Roberts B, Toole JF. Reversal of blood flow through the vertebral artery and its effect on cerebral circulation. $N$ Engl J Med 1961; 265: 878-85.

7. Vollmar J, Elbayar M, Kolmar D, Pfleiderer T, Diezel PB. Cerebral circulatory insufficiency in occlusive processes of the subclavia artery (,subclavial steal effect").[German]. Dtsch Med Wochenschr 1965; 90: 8-14.

8. Branchereau A, Magnan PE, Espinoza H, Bartoli JM. Subclavia artery stenosis: hemodynamic aspects and surgical outcome. J Cardiovasc Surg (Torino) 1991; 32: 604-12.

9. Reders M. Gamuts in radiology. 4th edition. New York: Springer Verlag; 2003. p. 87.

10. Bornstein NM, Norris JW. Subclavia steal: a harmless haemodynamic phenomenon? Lancet 1986; 2: 303-5.

11. Ackermann H, Diener HC, Seboldt H, Huth C. Ultrasonographic follow-up of subclavia stenosis and occlusion: natural history and surgical treatment. Stroke 1988; 19: 431-5.

12. Kliewer MA, Hertzberg BS, Kim DH, Bowie JD, Courneya DL, Carroll BA. Vertebral artery Doppler waveform changes indicating subclavia steal physiology [published erratum appears in AJR Am J Roentgenol 2000; 174(5): 1464]. AJR Am J Roentgenol 2000; 174(3): 815-9.

13. Stephan Wetzel, Georg Bongartz. Carotid and vertebral arteries MRA (Magnetic resonance angiography). $2^{\text {nd }}$ revised edition. Berlin: Springer; 2002. p. 22834.

14. Auer A, Felber S, Schmidauer C, Waldenberger P, Aichner F. Magnetic resonance angiographic and clinical features of extracranial vertebral artery. $J$ Neurosurg Psychiatry 1998; 64: 474-81.

15. Carriero A, Salute L, Tartaro A. The role of magnetic resonance angiography in the diagnosis of subclavia steal. Cardiovasc Intervent Radiol 1995; 18: 87-91. 
16. Hebrang A, Maskovic J, Tomac B. Percutaneous transluminal angioplasty of the subclavia arteries: long- term results in 52 patients. AJR Am J Roentgenol 1991; 156: 1091-4.

17. Kaufman JA, Lee MJ, Vascular and interventional radiology. $1^{\text {st }}$ edition. Oregon: Mosby; 2002. p. 1-26; 83-6; 146-6.

18. Kandarpa K, Aruny JE. Handbook of interventional radiologic procedures. $3^{\text {rd }}$ edition. New York: Lippincot Williams \& Wilkins; 2002. p. 1-26; 7480 .

19. Sutton David et al. Textbook of radiology and imaging. Vol 1 and 2. $6^{\text {th }}$ edition. London: Churchill Livingstone; 2000. p. 1557-8.

20. Stockel D, Pelton A, Duerg T. Self expanding nitinol stents: material and desing considerations. Eur Radiology 2004; 14: 292-301.

21. De Vries JP, Jager LC, Van den Berg JC, Overtoom TT, Ackerstaff RG, Van de Pavoordt ED, et al. Durability of percutaneous transluminal angioplasty for obstructive lesions of proximal subclavia artery: long-term results. J Vasc Surg 2005; 41: 19-23.

22. Rodriguez-Lopez JA, Werner A, Martinez R, Torruella LJ, Ray LI, Diethrich EB. Stenting for atherosclerotic occlusive disease of the subclavia artery. Ann Vasc Surg 1999; 13: 254-60.

23. Deriu GP, Milite D, Verlato F, Cognolato D, Frigatti $\mathrm{P}$, Zaramella M, et al. Surgical treatment of atherosclerotic lesions of subclavia artery: carotid-subclavia bypass versus subclavia-carotid transposition. J Cardiovasc Surg (Torino) 1998; 39: 729-34.

24. Edwards WH Jr, Tapper SS, Edwards WH Sr, Mulherin JL Jr, Martin RS 3rd, Jenkins JM. Subclavia revascularization. A quarter century experience. Ann Surg 1994; 219: 673-7; discussion 677-8.

25. Rehders TC, Petzsch M, Ince H, Kische S, Korber $\mathrm{T}$, Koschyk DH, et al. Intentional occlusion of the left subclavia artery during stent-graft implantation in the thoracic aorta: risk and relevance. $J$ Endovasc Ther 2004; 11: 659-66.

26. Rodriguez-Lopez JA, Werner A, Martinez R, Torruella LJ, Ray LI, Diethrich EB. Stenting for atherosclerotic occlusive disease of the subclavia artery. Ann Vasc Surg 1999; 13: 254-60. 